\title{
A 6.7 Mortality method for repair of ruptured Abdominal Aortic Aneurysm as presented at the American college of surgeons meeting at Chicago, IL on 10/13/09
}

\author{
Randecker $\mathbf{H}^{*}$ \\ Department of Cardiothoracic Surgery, Pasadena Bayshore Hospital, Pasadena, WA, USA
}

\begin{abstract}
The incidence of ruptured abdominal aortic aneurysms is approximately 3.4/100000 in the general population with a surgical incidence of 31100000 . For patients treated in the USA in 1994, the operative mortality was 68\% (4516 deaths/6623 surgeries) per the National Hospital Discharge Survey (CR) data base.

In 39 research articles with the lowest mortality utilizing the conventional method of repair of ruptured abdominal aortic aneurysms (CR), there were 8625 deaths/1765 patients with an average mortality of $49 \%$ with a range 30 to 90 . Other surgical tearns at one of the author's hospitals used the CR protocol (drawn from the same population) experienced a $75 \%$ mortality over a 7 -year period.
\end{abstract}

\section{Introduction}

The incidence of ruptured abdominal aortic aneurysms is approximately $3.4 / 100000$ in the general population with a surgical incidence of 31100000 [1]. For patients treated in the USA in 1994, the operative mortality was $68 \%$ (4516 deaths/6623 surgeries) per the National Hospital Discharge Survey (CR) data base [1].

In 39 research articles with the lowest mortality utilizing the conventional method of repair of ruptured abdominal aortic aneurysms (CR), there were 8625 deaths/1765 patients with an average mortality of $49 \%$ with a range 30 to 90 [2-40]. Other surgical tearns at one of the author's hospitals used the CR protocol (drawn from the same population) experienced a $75 \%$ mortality over a 7 -year period.

The SSHP includes 15 patients with $0 \%$ mortality at 21 days and 1 death at 30 days for a mortality of $6.7 \%$. Prior to the development of the SSHP, the author's mortality on these patients was $\sim 50 \%$.

\section{Material}

This report covers 15 consecutive patients treated by the SSHP. These surgeries were performed at four different hospitals with the author as the only surgeon. In one hospital $<40$ elective abdominal aortic aneurysm was performed/year and in a second hospital no elective aortic aneurysm repairs were performed/year. Two other hospitals had small active open-heart surgery programs. These for-profit community or district hospitals had no residency programs, were not part of any university system, and had $<200$ beds.

\section{Patient demographics}

The SSHP patients' demographics were compared with a "indirect historic control" (Table 1) of 2058 patients with a 48 mortality from within the CR group $[2,4,15,16,19-21,25,28,32,34,38,40]$. The SSHP group had a significantly higher percentage of patients with hypotension, syncope, $>80 \mathrm{y} / \mathrm{o}$, and carotid artery/peripheral vascular

\begin{tabular}{|c|c|c|}
\hline CONDITION & $\begin{array}{l}\text { of CR PATIENTS with } \\
\text { CONDITION }\end{array}$ & $\begin{array}{l}\text { of SSHP PATIENTS with } \\
\text { CONDITION }\end{array}$ \\
\hline COLLAPSE & $30 \%$ & $7 \%$ \\
\hline SYNCOPE & $14 \%$ & $73 \%$ \\
\hline HYPOTENSION $<100 \mathrm{~mm} . \mathrm{Hg}$ & $45 \%$ & $87 \%$ \\
\hline RESPIRATORY ARREST & & $13 \%$ \\
\hline CARDIAC ARREST & $8 \%$ & $7 \%$ \\
\hline PRE-OP MYOCARDIAL & $22 \%$ & $27 \%$ \\
\hline \multicolumn{3}{|l|}{ INFARCTION } \\
\hline CORONARY ARTERY DIS. & $31 \%$ & $33 \%$ \\
\hline CAROTID ARTERY DIS. & $6 \%$ & $27 \%$ \\
\hline HYPERTENSION & $30 \%$ & $40 \%$ \\
\hline PERIPHERAL VASCULAR & $16 \%$ & $27 \%$ \\
\hline \multicolumn{3}{|l|}{ DIS. } \\
\hline RENALDIS. & $5 \%$ & $7 \%$ \\
\hline C.O.P.D. & $15 \%$ & $20 \%$ \\
\hline ARRYTIIMIAS & $15 \%$ & $20 \%$ \\
\hline$>80$ YEARS OLD & $15 \%$ & $27 \%$ \\
\hline MALE & $78 \%$ & $73 \%$ \\
\hline FEMALE & $22 \%$ & $27 \%$ \\
\hline BLACK & $6 \%$ & $7 \%$ \\
\hline HISPANIC & & $13 \%$ \\
\hline MORTALITY & $48 \%$ & $7 \%$ \\
\hline SMOKING HISTORY & & $60 \%$ \\
\hline ANTI-COAGULATION/ & & $33 \%$ \\
\hline COUMADIN & & \\
\hline
\end{tabular}

*Correspondence to: Randecker H, Department of Cardiothoracic Surgery, Pasadena Bayshore Hospital, Pasadena, WA, USA, Tel: 4258290700; Fax: 2532163635; E-mail: hrandecker@earthlink.net

Received: December 21, 2018; Accepted: January 03, 2019; Published: January 07,2019 
disease. No patients in this historic meta-analysis had pre-operative diabetes mellitus. Survival rates are given at 45 days for SSHP Since the early mortality of the SSHP appeared to be $15 \%$ versus $49 \%$ in the CR protocols, doing a 1: 1 prospective study might not have met ethical standards.

\section{Aneurysm pathology}

Aneurysm size in 14 of the patients varied from 6 to $11 \mathrm{~cm}$. in diameter and 8 to $15 \mathrm{~cm}$. in length. $20 \%$ of the patients had bilateral common iliac artery aneurysms with the tear extending from the aorta into one of the common iliac artery aneurysms. $7 \%$ of the patients had supra-renal extension of the aneurysm.

\section{Method}

All patients and/or their relatives were informed of the risks \& benefits of the SSHP, alternative procedures, and signed operative permits. The fifteen specialized SSHP patients were treated as follows:

1) After the diagnosis is determined and if there is a "spark" of life no time is wasted in getting the patient to the operating room. Aneurysm neck position is determined by a very rapid limited non-contrast abdominal C-T exam if the patient is stable enough to tolerate the exam and no abdominal $\mathrm{C}$ - $\mathrm{T}$ was done during the diagnostic work-up. No effort is made to determine if the patient will survive surgery.

2) Minimal pre-operative volume expansion with crystalloid/blood is acceptable in the ambulance and/or emergency room to attempt to increase the systolic blood pressure to $>60 \mathrm{~mm}$. $\mathrm{Hg}<80 \mathrm{~mm}$. Hg. if needed to maintain cardiac function. A thready pulse palpable anywhere is acceptable. Patients in the SSHP were not adversely affected by transport distance and/or hypotension as long as they were not over hydrated. Raising blood pressure can blow away nature's "patch". This "patch" consists of the retroperitoneal hematoma over the blow-out site and the pressure developed on this hematoma by an intact retroperitoneal fascia, posterior and anterior abdominal wall musculature which balances against the decreased intra-aortic pressure. Pre-operative re-perfusion to near physiologic levels will result in destruction of this fragile equilibrium resulting in intra-peritoneal cavity hemorrhage. Due to the insistence on under-hydration, the aorta remains flaccid (facilitating it's surgical dissection; see section 5) and minimal to no intra-peritoneal hemorrhage was encountered in all cases.

3) An intra-operative blood recovery machine (cell saver) is used to decrease the amount of transfused blood components. Perioperative blood replacement in the specialized SSHP cases was 5 units of blood bank packed red cells (PRC) and 5 units of cell saver PRCs with average operative blood replacement of 10 units PRCs.

4) All measures were employed to avoid hypothermia as it has severe adverse effects on coagulability, cardiac function, and re-perfusion. This is very hard if not impossible to reverse in a small community hospital setting. Prevention can be difficult but is facilitated by: warming the operating room to 75 to 80 degrees; placing warming blankets (Bair Hugger/Arizant) on the extremities, chest and head; hot saline irrigation of the peritoneal cavity and its contents; and warming to physiologic temperatures of intravenous fluids, banked blood and blood products, cell saver blood, and medications.

5) This is the essence of the SSHP. The abdomen is opened with a standard midline abdominal incision from xiphoid to pubic symphysis and the bowel is eviscerated very rapidly, which may cause tears of the bowel if adhesions are present. Clamp the tears in the bowel and keep moving. Next, the retroperitoneum over the proximal dome of the aneurysm is opened without regard to intraperitoneal blood or bleeding from the hematoma There is no direct visualization after this point. The surgeon's hand follows the proximal dome of the aneurysm to the lumbar vertebrae and the thread pulse on top of it This is the surgical neck of the aneurysm and it is bluntly dissected free of the left sided retroperitoneal structures including inferior mesenteric vein. The surgical neck has been elevated from the lumbar vertebrae by growth of the posterior portion of the aneurysm. The lumbar arteries and veins are elongated by the growth of the posterior body of the aneurysm. The hypotensive aorta (section 3) is flaccid. These two events create a space large enough for the surgeon's right index finger to easily enter (Figure 1). The lumbar arteries and veins will feel like tight sutures. The aorta is manually clamped between the thumb and index finger in the first three to four minutes of opening the abdomen. No evidence of the aneurismal wall tear was found to be extending into the surgical neck of any of the 15 aneurysms. While the anesthesiologist is stabilizing the patient, dissection of the flaccid aorta from the inferior vena cava is accomplished. Arterial lines and central venous Swan-Ganz catheter lines are inserted during stabilization. Stabilization includes full volume replacement to physiologic blood pressure, control of acid base balance, and restoration of urine output. Digital control is then switched to clamp control of the surgical neck. The iliac artery system back-bleeding is initially controlled either by manual compression of the distal aorta and iliac systems by an assistant or Fogarty catheter insertion until the mechanical cross clamp of the aortic neck of the aneurysm is completed. Fogarty catheter insertion is completed or direct clamping of the iliac arteries/distal aorta for occlusion is done after mechanical cross clamping of the surgical neck is completed. Of all the cross-clamp locations including intra-thoracic, supra-renal and endovascular balloon occlusion. cross clamping at the surgical neck of the ruptured aneurysm decreases visceral and renal blood flow the least and therefore tends to be the least physiologically disruptive of organ function. This diminishes the amount of Iiver/ renal/visceral ischemia and necrosis with subsequent lactic acidosis, release of cardiac toxins and toxin interference with the clotting cascade. Laceration of a section of small bowel with spillage from the laceration occurred in one patient upon taking down adhesions on entry. This was clamped and after the ruptured aneurysm was

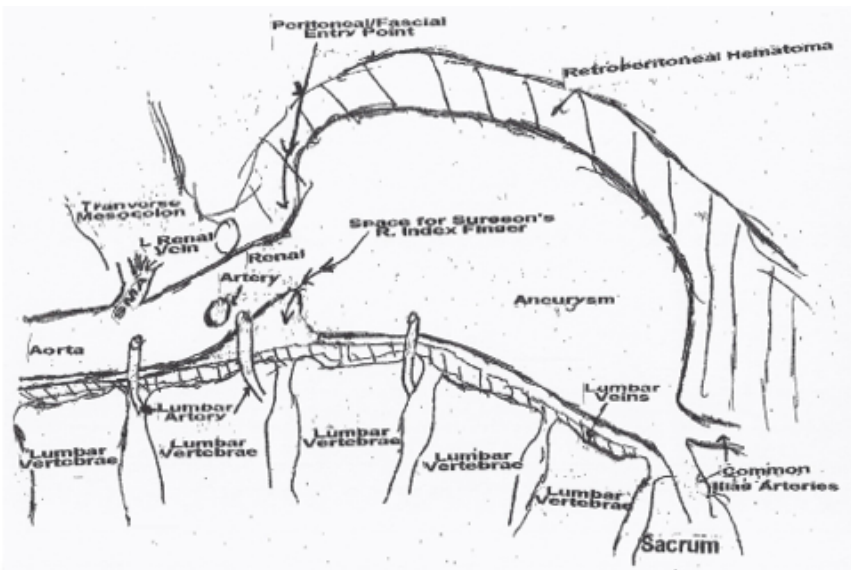

Figure 1. Lateral View Showing Surgical neck of the Ruptured Aortic Aneurysm diagram not to scale \& is generic 
repaired, the bowel was repaired. With $>12$ month follow up no graft infection occurred. Division of the left renal vein with repair at the end of the case and implantation of the inferior mesenteric artery can be used if needed, but these options were not utilized in this series. 6) The use of less than 2000 units of heparin for the whole case including monitoring lines and cell saver is the ideal. Systemic heparin dose is approximately 2000 units. This dose created no bleeding problems in 12 patients. Missing this ideal goal; and giving $>3500$ units led to fortunately reversible difficulties in 3 patients. No attempt was made to reverse chronic pre -operative Coumadin. NO systemic heparinization was given. 7) Tube and bifurcated woven Dacron grafts were used. If common iliac artery aneurysms are present. If the aortic bifurcation is unrepairable, it is excluded using a bifurcated graft.

8) Do only enough surgery to get the patient out of the operating room alive. A Fogarty catheter is used to retrieve clots and debris from the iliac and proximal femoral artery systems. New clots are formed in the graft and aorta. They are expected and removed using suction attached to the cell saver. If proximal lower extremities are remotely viable, no other repair should be attempted.

9) Post-operative care should mimic that given to "sick" post-operative open-heart surgery patients including vigorous rhythm control, cardioversion, diuretics, and volume replacement. This replacement in order of preference is: packed red blood cells, fresh frozen plasma, platelet packs, cryoprecipitate, Hespan, \& crystalloids.

\section{Result}

15 of 15 patients survived for 21 days for a $0 \%$ mortality. 14 of the 15 SSHP patients survived $>45$ days for a mortality of $6.7 \%$. No intra- operative mortality occurred. Surgery averaged 199 minutes (70 to 365): Aortic clamp time averaged 109 minutes (45 to 170).

\section{Mortality}

The only post-operative mortality occurred in a 77 ylo female who had muscular dystrophy. Due to this muscular dysfunction of her chest wall she could not cough effectively. This obese patient had a pre-operative pneumonia and multiple $90 \%$ LAD coronary artery stenoses. Greater than 3500 units of heparin were given during a successful surgery. A post- operative abdominal wall hematoma requiring surgical evacuation occurred followed by a peri-operative myocardial infarction. On her 14th post-operative day, she developed a right lower lobe abscess, septicemia, multi-organ failure, and acute renal tubular necrosis (ATN) requiring dialysis. She expired after 21 days.

\section{Morbidity}

$14 \%$ had ATN that required up to 2 dialysis runs for resolution. $14 \%$ had pre-operative chronic renal failure with creatinines of $1.6 \& 2.2$ progressing to $9.0 \& 2.8$ prior to returning to $1.3 \& 2.1$ at discharge. All other complications are listed in Table 2 and were successfully treated.

\section{Discussion}

CR group surgeons tended to employ 3 to 5 of the SSHP concepts. They either do not use surgical neck cross-clamp or if they do, they do not use much of the rest of the SSHP.

Where enough CR report surgical technique details are available $[2,3,5,7,28,30,39]$ the mortality is 47 with 1095 deaths/2890 patients. There is a statistically Significant difference in mortality $(\mathrm{p}<.001$; two

\section{Table 2. Morbidity}

\begin{tabular}{|l|c|}
\hline Acute Transient Renal Failure NO Dialysis & $7 \%$ \\
\hline Acute Tubular Necrosis - Short Term Dialysis & $20 \%$ \\
\hline Iatrogenic Sigmoid Colon Trauma & $7 \%$ \\
\hline Prolonged Assisted Ventilation & $27 \%$ \\
\hline Deep Venous Thrombosis & $7 \%$ \\
\hline $\begin{array}{l}\text { Diverting Ileostomy for Massive Fecal Concretions /Diverticulosis Sigmoid } \\
\text { Colon }\end{array}$ & $7 \%$ \\
\hline $\begin{array}{l}\text { Surgical Evacuation Abdominal Wall Hematoma } \\
\text { heporacotomy for Evacuation of Thoracic Mediastinal Hematoma 2nd to }\end{array}$ & $7 \%$ \\
\hline
\end{tabular}

tailed test) when compared to the mortality of the SSHP. A statistic's probability of being correct or true is delineated from standard mathematical equations and tables that produce a number (,1 to .0001). The smaller the number, the closer to "true" the statistic is and the more likely the results are to be repeatable. In other words, even though there are only 15 SSHP patients in this study, if the study were continued, 14 consecutive deaths would be required for the mortality of this technique to be $50 \%$ (CR) or 3 deaths in the next 4 patients for a $25 \%$ mortality (CA). Much attention has been paid in some research papers $[1,2,5,16,17,21,22,27,41]$ to determining which patients with ruptured abdominal aortic aneurysms to treat because of the waste of scarce resources on the $30 \%$ to $70 \%$ of patients unlikely to survive. Hospital costs, lack of adequate reimbursement, depletion of blood bank stores, and remaining quality of life are often cited in this discussion. SSHP take all patients without trying to determine who will live or die. The remaining quality of life after 45 days for SSHP patients is about the same as for a coronary artery bypass patient $[13,41-47]$. SSHP patients went on to resume their life styles with the expected gradual downward spirals from associated disease processes. In view of the low mortality of the SSHP, the expenses and reimbursements for these patients should be the same as for moderately "sick" coronary artery bypass patients.

The retro-peritoneal hematoma contains 1 to 3 liters of clotted blood and will be several hundred CC.S of blood in the peritoneal cavity, drapes, sponges, and "cell saver". All of the blood in these areas represents lost clotting factors. One third of the patients in SSHP were clinically anti-coagulated with Coumadin (1 with an INR of 3.5) and this is not reversible. The use of $<3000$ units of heparin total from "cell saver", and monitoring line heparin, does not seem to disturb the ability of the remaining clotting system to make clots. The surgeon must be ready to suction new clots from the lumens of tube and bifurcated grafts and use Fogarty catheters and back-bleeding of the iliac system to clear clots without feeling pressure to fully anti- coagulate the patient, The reward is that these patients do not bleed out through their incisions and graft walls in the operating room or the ICU, the operation takes much less time, and the post-operative course is much smoother.

The basic aim of the SSHP is to save the patient's life. Doing additional re-vascularization, while convenient at the time of the initial surgery, uses up clotting factors, requires more heparin, exposes the patient to more anesthesia, increases hypothermia, increases acidosis, increases cardiotoxins, and increases post-operative metabolic! cardiac requirements. Additional vascular repairs can be done as needed in the mid to late post-operative period.

The equipment used in the SSHP can be found in any hospital capable of rudimentary vascular surgery in this country or elsewhere in the world. All the SSHP requires is a change in the thinking processes of the surgeon and in surgical training. 
Randecker H (2019) A 6.7 Mortality method for repair of ruptured Abdominal Aortic Aneurysm as presented at the American college of surgeons meeting at Chicago, IL on 10/13/09

The SSHP needs an expanded clinical trial to determine if other surgical groups can match or, as I suspect, improve on these results. If this can be accomplished, the dismal outlook for patients with ruptured abdominal aortic aneurysms would be improved, especially in areas where more limited medical facilities are available.

\section{References}

1. Lawrence PF, Gazak C, Bhirangi L, Jones B, Bhirangi K, et al. (1999) The epidemiology of surgically repaired aneurysms in the United States. J Vasc Surg 30 632-640. [Crossref]

2. Johansan K, Kohler TR, Nichols SC, Zierler RE, Clowes AW, et al. (1991) Ruptured Abdominal Aortic Aneurysm: the Harbor view experience. J Vasc Surg 13: 240-45. [Crossref]

3. Darling RC 3, Cordero JA Jr, Chang BB, Shah DM, Paty PS, et al. (1996) Advances in the surgical repair of ruptured abdominal aortic aneurysms. Cardiovasc Surg 4: 720723. [Crossref]

4. Dardik A, Burleyson GP, Bowman H, Gordon TA, Williams GM, et al. (1998) Surgical repair of ruptured abdominal aortic aneurysms in the state of Maryland: factors influencing outcome among 527 recent cases. J Vasc Surg 28: 413-420. [Crossref]

5. Hardman DT, Fisher CM, Patel MI, Neale M, Chambers J, et al. (1996) Ruptured abdominal aortic aneurysms: who should be offered surgery? J Vasc Surg 23: 123-129. [Crossref]

6. Katz DJ, Stanley JC, Zelenock GB (1994) Operative mortality rates for intact and ruptured abdominal aortic aneurysms in Michigan: an eleven-year statewide experience. J Vasc Surg 19: 804-815. [Crossref]

7. Manheim LM, Sohn MW, Feinglass J, Ujiki M, Parker MA, et al. (1998) Hospital vascular surgery volume and procedure mortality rates in California, 1982-1994. J Vasc Surg 28: 45-56. [Crossref]

8. Wen SW, Simunovic M, Williams JI, Johnston KW, Naylor CD (1996) Hospita volume, calendar age, and short-term outcomes in patients undergoing repair of abdominal aortic aneurysms: the Ontario experience, 1988-92. J Epidemiol Community Health 50: 207-213. [Crossref]

9. Hannan EL, Kilburn H Jr, O'Donnell JF, Bernard HR, Shields EP, et al. (1992) A longitudinal analysis of the relationship between in-hospital mortality in New York State and the volume of abdominal aortic aneurysm surgeries performed. Health Serv Res 27: 517-542. [Crossref]

10. Wang GJ, Carpenter JP; Endologix Investigators (2008) The Powerlink system for endovascular abdominal aortic aneurysm repair: six-year results. $J$ Vasc Surg 48: 535545. [Crossref]

11. Patel ST, Korn P, Haser PB, Bush HL Jr, Kent KC (2000) The cost-effectiveness of repairing ruptured abdominal aortic aneurysms. J Vasc Surg 32: 247-257. [Crossref]

12. Burke PM Jr, Sannella NA (1993) Ruptured abdominal aortic aneurysm: a community experience. Cardiovasc Surg 1: 239-242. [Crossref]

13. Rohrer MJ, Cutler BS, Wheeler HB (1988) Long-term survival and quality of life following ruptured abdominal aortic aneurysm. Arch Surg 123: 1213-1217. [Crossref]

14. Dean RH, Woody JD, Enarson CE, Hansen KJ, Plonk GW Jr (1993) Operative treatment of abdominal aortic aneurysms in octogenarians. When is it too much too late? Ann Surg 217: 721-728. [Crossref]

15. Seiwert AJ1, Elmore JR, Youkey JR, Franklin DP (1995) Peter B. Samuels Award. Ruptured abdominal aortic aneurysm repair: the financial analysis. Am J Surg 170: 91-96. [Crossref]

16. Chen JC, Hildebrand HD, Salvian AJ, Taylor DC, Strandberg S, et al. (1996) Predictors of death in nonruptured and ruptured abdominal aortic aneurysms. J Vasc Surg 24: 614-620. [Crossref]

17. Panneton JM, Lassonde J, Laurendeau F (1995) Ruptured abdominal aortic aneurysm: impact of comorbidity and postoperative complications on outcome. Ann Vasc Surg 9: 535-541. [Crossref]

18. Gloviczki P, Pairolero PC, Mucha P Jr, Farnell MB, Hallett JW Jr, et al. (1992) Ruptured abdominal aortic aneurysms: repair should not be denied. J Vasc Surg 15:8517. [Crossref]

19. Martin RS, Edwards WH Jr, Jenkins JM, Edwards WH Sr, Mulherin JL (1988) Ruptured abdominal aortic aneurysm: a 25-year experience and analysis of recent cases. Am Surg 54: 539-543. [Crossref]
20. Chen JC, Hildebrand HD, Salvian AJ, Hsiang YN, Taylor DC (1997) Progress in abdominal aortic aneurysm surgery: four decades of experience at a teaching center. Cardiovasc Surg 5: 150-156. [Crossref]

21. Shackleton CR, Schechter MT, Bianco R, Hildebrand HD (1987) Preoperative predictors of mortality risk in ruptured abdominal aortic aneurysm. J Vasc Surg 6: 583589. [Crossref]

22. Wakefield TW, Whitehouse WM Jr, Wu SC, Zelenock GB, Cronenwett JL, et al. (1982) Abdominal aortic aneurysm rupture: statistical analysis of factors affecting outcome of surgical treatment. Surgery 91: 586-596. [Crossref]

23. Ouriel K, Geary K, Green RM, Fiore W, Geary JE, et al. (1990) Factors determining survival after ruptured aortic aneurysm: the hospital, the surgeon, and the patient. $J$ Vasc Surg 11: 493-496. [Crossref]

24. Katz SG, Kohl RD (1994) Ruptured abdominal aortic aneurysms. A community experience. Arch Surg 129: 285-290. [Crossref]

25. Koskas F, Kieffer E (1997) Surgery for ruptured abdominal aortic aneurysm: early and late results of a prospective study by the AURC in 1989. Ann Vasc Surg 11: 90-99. [Crossref]

26. Halpern VJ, Kline RG, D'Angelo AJ, Cohen JR (1997) Factors that affect the surviva rate of patients with ruptured abdominal aortic aneurysms. J Vasc Surg 26: 939-945. [Crossref]

27. Evans SM, Adam DJ, Bradbury AW (2000) The influence of gender on outcome after ruptured abdominal aortic aneurysm. J Vasc Surg 32: 258-262. [Crossref]

28. Lawler M Jr (1984) Aggressive treatment of ruptured abdominal aortic aneurysm in a community hospital. Surgery 95: 38-44. [Crossref]

29. Shumakar HB Jr, Barnes DL, King H (1973) Ruptured abdominal aortic aneurysms. Ann Surg 177:772-9

30. McCready RA, Siderys H, Pittman JN, Herod GT, Halbrook HG, et al. (1993) Ruptured abdominal aortic aneurysms in a private hospital: a decade's experience (1980-1989). Ann Vasc Surg 7: 225-228. [Crossref]

31. Scobie TK, Masters RG (1982) Changing factors influencing abdominal aortic aneurysm repair. J Cardiovasc Surg 23:309-313. [Crossref]

32. DiGiovanni R, Nicholas G, Volpetti G, Berkowitz H, Barker C, et al. (1975) Twentyone years' experience with ruptured abdominal aortic aneurysms. Surg Gynecol Obstet 141: 859-862. [Crossref]

33. Gaylis H, Kessler E (1980) Ruptured aortic aneurysms. Surgery 87: 300-304 [Crossref]

34. Donaldson MC, Rosenberg JM, Bucknam CA (1985) Factors affecting survival after ruptured abdominal aortic aneurysm. J Vasc Surg 2: 564-570. [Crossref]

35. Fielding JL, Black J, Ashton F, Slaney G (1984) Ruptured aortic aneurysms postoperative complications and their aetiology. Br J Surg 71: 487-491. [Crossref]

36. Hoffman M, Avellone JC, Plecha FR, Rhodes RS, Donovan DL, et al. (1982) Operation for ruptured abdominal aortic aneurysms: a community-wide experience. Surgery 91 597-602. [Crossref]

37. Vohra R, Abdool-Carrim AT, Groome J, Pollock JG (1988) Evaluation of factors influencing survival in ruptured aortic aneurysms. Ann Vasc Surg 2: 340-344. [Crossref]

38. Crew JR, Bashour TT, Ellertson D, Hanna ES, Bilal M (1985) Ruptured abdomina aortic aneurysms: experience with 70 cases. Clin Cardiol 8: 433-436. [Crossref]

39. Donaldson MC, Rosenberg JM, Bucknam CA (1985) Factors affecting survival after ruptured abdominal aortic aneurysm. $J$ Vasc Surg 2: 564-570. [Crossref]

40. Barry MC, Burke PE, Sheehan S, Leahy A, Broe PJ, et al. (1998) An "all comers" policy for ruptured abdominal aortic aneurysms: how can results be improved? Eur J Surg 164: 263-270. [Crossref]

41. Chiariello L, Reul GJ Jr, Wukasch DC, Sandiford FM, Hallman GL, et al. (1974) Ruptured abdominal aortic aneurysm. Treatment and review of eighty-seven patients. Am J Surg 128: 735-738. [Crossref]

42. Lawrie GM, Morris GC Jr, Crawford ES, Howell JF, Whisennand HH, et al. (1979) Improved results of operation for ruptured abdominal aortic aneurysms. Surgery 85: 483-488. [Crossref]

43. Crawford ES (1991) Ruptured abdominal aortic aneurysm. J Vasc Surg 13: 348-350. [Crossref] 
Randecker H (2019) A 6.7 Mortality method for repair of ruptured Abdominal Aortic Aneurysm as presented at the American college of surgeons meeting at Chicago, IL on 10/13/09

44. Marty-Ané CH, Alric P, Picot MC, Picard E, Colson P, et al. (1995) Ruptured abdominal aortic aneurysm: influence of intraoperative management on surgical outcome. $J$ Vasc Surg 22: 780-786. [Crossref]

45. El-Sabrout RA, Reul GJ (2001) Suprarenal or supraceliac aortic clamping during repair of infrarenal abdominal aortic aneurysms. Tex Heart Inst $J$ 28: 254-264. [Crossref]
46. Hsiang YN, Turnbull RG, Nicholls SC, McCullough K, Chen JC, et al. (2001) Predicting death from ruptured abdominal aortic aneurysms. Am J Surg 181: 30-35. [Crossref]

47. Veith FJ, Dente KM (2006) Expert says data support endovascular aneurysm repair Neith Symposium Montefiore Medical Center. Surgery News Elseveier.

Copyright: @2019 Randecker H. This is an open-access article distributed under the terms of the Creative Commons Attribution License, which permits unrestricted use, distribution, and reproduction in any medium, provided the original author and source are credited. 